\title{
Bariatric surgery for obesity: a systematic review and meta-analysis
}

\begin{abstract}
Obesity is the fifth leading cause of global deaths. The efficacy and safety of obesity treatment is still controversial. The objective of the study is to evaluate the efficacy of bariatric surgery, through a systematic review of the current evidence and metaanalysis of important outcomes. Nineteen (19) randomized controlled trials (RCTs) with 1346 participants were included. Bariatric surgery resulted in greater weight loss when compared to non-surgical treatment. Weight loss was also associated with resolution and/or improvement of obesity related co-morbidities such as diabetes, hypertension, hyperlipidemia and sleep apnea. Weight loss and safety varied across the surgical procedures. Biliopancreatic diversion/duodenal switch had the greatest weight loss, followed by sleeve gastrectomy and Roux-en-Y gastric bypass, purely restrictive procedures such as vertical banded gastroplasty and adjustable gastric banding resulted in the least weight loss.
\end{abstract}

Keywords: obesity/surgery, gastric bypass, sleeve gastrectomy, bariatric, gastric banding, anastomosis, roux-en-y, biliopancreatic diversion (including duodenal switch)
Volume 2 Issue 2 - 2015

\author{
Hakeem Alobaid, Aziz Alsadoon, Karim M \\ Eltawil, George A Wells \\ Department of Bariatric Surgery, Laval University, Canada
}

Correspondence: Hakeem Alobaid, Department of Bariatric Surgery, Laval University 2725 Chemin Ste-Foy, Quebec City, Quebec, Canada,Tel (+00I) 6137976666;

Email alobaid.ah@gmail.com

Received: January 30, 2015 | Published: February 14, 2015
Abbreviations: RCTs, randomized controlled trials; BMI, body mass index; WHO, world health organization; BPD, biliopancreatic diversion; EWL, excess weight loss; MD, mean difference; SE, standard error; CI, confidence interval; $\mathrm{MeSH}$, medical subject headings

\section{Introduction}

Overweight and obesity represent a major health challenge and are considered to be the fifth leading risk for global death and a major burden on health care systems. ${ }^{1}$ Body Mass Index (BMI) is the most commonly used measure for classifying overweight and obesity in adults. The World Health Organization (WHO) defines overweight as a BMI of 25 or more, obesity as a BMI of 30 or more and morbid obesity as a BMI of 40 or more. ${ }^{2}$ In the US, the prevalence of overweight and obesity in adults is estimated at $66.3 \%$ and $32.2 \%$ respectively ${ }^{3}$ and the prevalence of morbid obesity is approximately $5.1 \%{ }^{4}$

Non-surgical options for treatment of obesity include behavioral modification (dietary modification, caloric restriction, enhanced physical activity and psycho-interventions), pharmacotherapy, with or without organization supervision. These treatment modalities generally achieve only minimal and often transient effects with poor long term results. ${ }^{5,6}$ The raise in the prevalence of obesity led to increase interest in the surgical approach to treat obesity, and in 1991, the National Institutes of Health established guidelines for surgical therapy of morbid obesity $(\mathrm{BMI} \geq 40$ or $\mathrm{BMI} \geq 35$ in the presence of significant co-morbidities) now known as bariatric surgery. ${ }^{7}$ In the recentyears, the demand for bariatric surgery has significantly increased; in 2008, approximately 350,000 operations were performed worldwide; 220,000 of these in the US and Canada.

The objectives of this study are to evaluate the effectiveness and safety of surgical and non- surgical treatments for obesity and whether they modify clinically important outcomes, including weight loss, comorbidity modifications to diabetes, hyperlipidemia, hypertension, and obstructive sleep apnea in adolescents and the adult obese population.

\section{Material and methods}

\section{Data source and study selection}

Randomized controlled trials (RCTs) comparing bariatric surgical procedures versus usual care (no treatment or medical management) or head- to-head comparisons of different surgical procedures were searched on the Ovid interface: MEDLINE Daily Update, MEDLINE In-Process \& Other Non-Indexed Citations (1950 to December 8 2012), EMBASE (1947 to December 8 2012) and the Cochrane Library (until the fourth quarter 2012). The search strategy used both controlled vocabulary - the National Library of Medicine's MeSH (Medical Subject Headings). The search was not restricted to language and studies for which only abstracts were available were not considered.

Two reviewers (Hakeem Alobaid and Joan Peterson) independently performed an initial screening of articles by examining titles, abstracts and keywords for relevance to the research question. In case of disagreement or in the presence of insufficient information, the full text of the study was reviewed for eligibility. The decision to include articles in this study was reached by consensus. In cases where consensus was not achieved, a third reviewer (George Wells) was added to the selection process.

\section{Inclusion and exclusion criteria}

A study was eligible for inclusion if it satisfied each of the criteria listed below:

1. Study design: Randomized controlled trial (RCT).

2. Population: Adults who fulfill the definition of obesity i.e. BMI more than 30, and adolescents who fulfill the definition of obesity for age, sex, and height. 
3. Interventions: Five types of bariatric surgery procedures; Rouxen-Y gastric bypass, vertical banded gastroplasty, adjustable gastric banding, biliopancreatic diversion (BPD) and sleeve gastrectomy.

Exclusion criteria were: studies conducted on pediatric patients and non-controlled trials were not considered for analysis. Furthermore, studies that compared different techniques of the same procedure were excluded as well as those who compared techniques that are no longer used (e.g. jejunoileal bypass).

\section{Outcomes}

The measured outcomes of this study included:

1. Weight modifications: Percent of excess weight loss (EWL), BMI loss, and weight changes $(\mathrm{Kg})$.

2. Co-morbidity modifications: Resolution of obesity related co-morbidities (diabetes, hyperlipidemia, hypertension, and obstructive sleep apnea).

\section{Data extraction}

One reviewer (Hakeem Alobaid) extracted data from the selected studies, and a second reviewer (Joan Peterson) checked the extracted data for accuracy. Any differences were resolved by consensus. The following variables were collected: the name of the primary author, journal and status of publication, country (countries) were the study was carried out, number of patients randomized in each group, mean age, study duration and inclusion and exclusion criteria. Clinical variables extracted were: patient weight, BMI, estimated weight loss (EWL), co-morbidity modifications to diabetes, hyperlipidemia, hypertension, and obstructive sleep apnea.

\section{Assessment of study quality}

Methodological quality of the studies was assessed using the SIGN50. A Guideline Developer's Handbook published by the Scottish Intercollegiate Guidelines Network $^{8}$ which considered the appropriateness and clarity of the question, randomization, concealment, blinding, baseline comparability, group difference, outcome measurement, drop out, intention-to-treat analysis, site result, overall bias, and funding.

The risk of bias in the included studies was assessed using The Cochrane Handbook for Systematic Reviews of Interventions ${ }^{9}$ which considered the following factors: sequence generation, concealment, blinding, incomplete data, selective reporting and other bias.

The same two reviewers independently assessed the quality of the included studies. Prior to assessment, a calibration exercise was undertaken to ensure consistency in assessing or scoring between the two reviewers. Differences were discussed and resolved by consensus. In cases where consensus was not achieved, the third reviewer assisted with the study quality assessment process.

\section{Statistical analysis}

RevMan $5.1^{10}$ was used to analyze the result of the studies. Data were summarized in the meta-analysis if they were both clinically and statistically homogeneous. A random effects model was employed. Continuous data was expressed as mean difference (MD). In the few studies where measures of variance were missing from a relevant article, it was imputed from other information provided by the article (e.g. standard error (SE), p-value, 95\% confidence interval (CI)).
Before the quantitative pooling of the results, the homogeneity of the clinical and methodological characteristics of included studies was evaluated. The characteristics reviewed included study design, inclusion and exclusion criteria, baseline demographics (age, gender), interventions, and clinical outcomes. Heterogeneity was measured with the $\mathrm{I}^{2}$ statistic, with $\mathrm{I}^{2} \geq 50 \%$ identifying substantial heterogeneity. ${ }^{11}$

\section{Results}

\section{Ascertainment of the studies}

After initial screening, a total of 2006 potential studies were identified. Hand searching of the bibliographies of key papers and contacting appropriate experts resulted in additional 125 records. A total of 2131 records were screened. We excluded 2026 based on title or abstract. We retrieved 105 full text articles. Eighty five articles were excluded after reviewing the full text. A total of 19 studies met the inclusion criteria for the qualitative synthesis and 18 articles met the inclusion criteria for the quantitative synthesis (Figure 1).

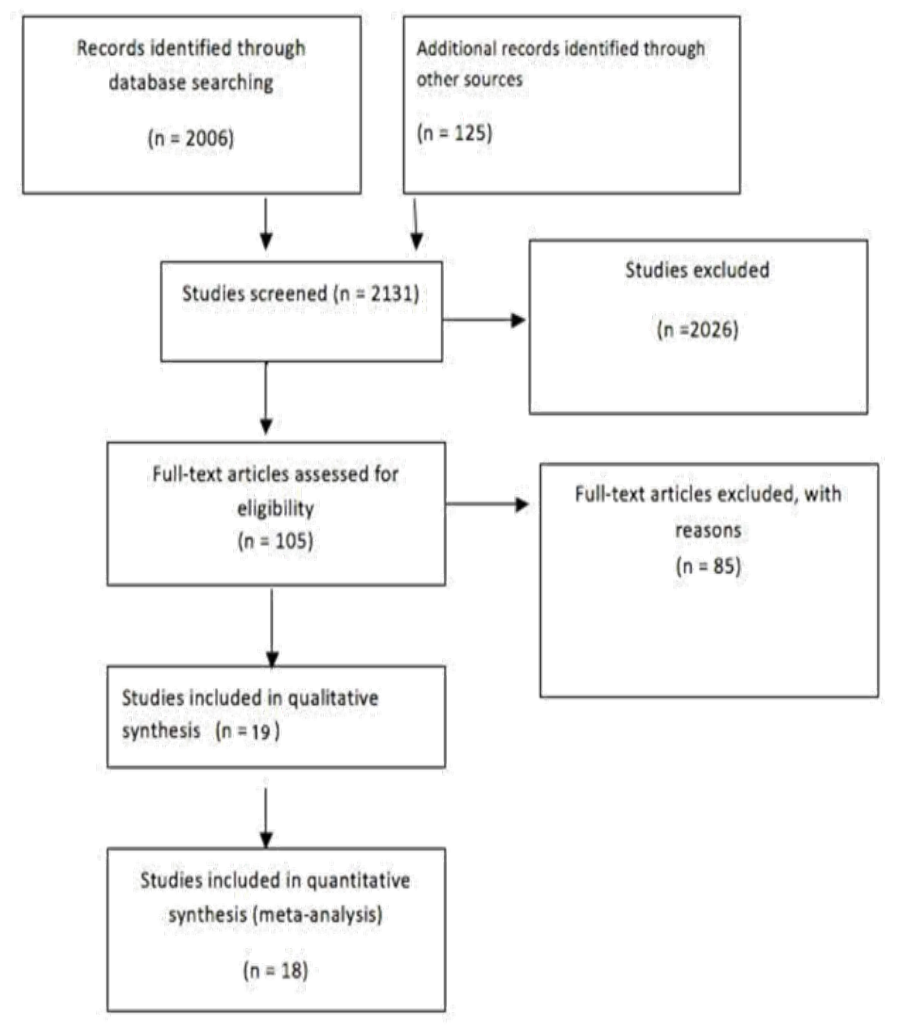

Figure I Search result flow diagram.

\section{Study Characteristics}

Table 1 summarizes the characteristics of all included studies. All the studies were single centre randomized control trials except for one trial $^{12}$ which was conducted in two centers. Sample size ranged from $20^{13}$ to $197 .{ }^{14}$ The included studies compared variety of interventions (Figure 2). Five RCTs ${ }^{13,15-18}$ compared surgical interventions to nonsurgical interventions.

Four of the five were done in an adult population ${ }^{13,16-18}$ and one RCT was done in an adolescent population. ${ }^{15}$ Fourteen RCTs compared different surgical procedures (Figure 2). 
Table I Characteristics of Included studies. ${ }^{12-30}$

\begin{tabular}{|c|c|c|c|c|c|}
\hline Study & Trial characteristics & $\begin{array}{l}\text { Patient } \\
\text { Characteristics }\end{array}$ & Interventions & Outcome & QA \\
\hline $\begin{array}{l}\text { Angrisani } \\
2007\end{array}$ & $\begin{array}{l}\text { Design: RCT, Single centre } \\
\text { Sample Size: } 5 \text { I } \\
\text { Follow-up: } 60 \text { months } \\
\text { Country: Italy }\end{array}$ & $\begin{array}{l}\text { Age: } 34(9) \\
\% \text { Female: } 82 \\
\text { BMI: } 43.6(4.1) \\
\text { WT: I I } 7.65(13)\end{array}$ & $\begin{array}{l}\text { I - LRYGBP } \\
\text { 2- LAGB }\end{array}$ & $\begin{array}{l}\text { BMI,Weight, \% EWL. } \\
\text { Mortality, conversion to an open procedure, postoperative } \\
\text { complications leading to reoperation, hospital stay, and } \\
\text { improvement in co-morbidities. }\end{array}$ & - \\
\hline $\begin{array}{l}\text { Dixon } \\
2008\end{array}$ & $\begin{array}{l}\text { Design: RCT, Single centre } \\
\text { Sample Size: } 60 \\
\text { Follow-up: } 24 \text { months } \\
\text { Country: Australia }\end{array}$ & $\begin{array}{l}\text { Age: } 46.8(8) \\
\% \text { Female: } 53.5 \\
\text { BMI: } 37.1(2.6) \\
\text { WT: } 105.7(14)\end{array}$ & $\begin{array}{l}\text { I- LAGB } \\
\text { 2- Conventional } \\
\text { treatment }\end{array}$ & $\begin{array}{l}\text { BMI,Weight, \% EWL. } \\
\text { Proportion of participants achieving remission of type } 2 \\
\text { diabetes, percentage change in Hb AIC levels, blood pressure, } \\
\text { waist circumference and levels of fasting lipids, including } \\
\text { total cholesterol, triglycerides, and high-density lipoprotein } \\
\text { cholesterol. } \\
\text { Changes in medication use, changes in the proportion of } \\
\text { participants with the metabolic syndrome, changes in indirect } \\
\text { measure of insulin resistance and adverse events. }\end{array}$ & + \\
\hline $\begin{array}{l}\text { Himpens } \\
2006\end{array}$ & $\begin{array}{l}\text { Design: RCT, Single centre } \\
\text { Sample Size: } 80 \\
\text { Follow-up: } 36 \text { months } \\
\text { Country: Belgium }\end{array}$ & $\begin{array}{l}\text { Age: } 38(20-65)^{*} \\
\text { \% Female: } 80 \\
\text { BMI: } 38(30-53)^{*} \\
\text { WT: not reported } \\
\text { *median \& range }\end{array}$ & $\begin{array}{l}\text { I- LSG } \\
\text { 2- LAGB }\end{array}$ & $\begin{array}{l}\text { BMI, weight, \% EWL. } \\
\text { Feeling of hunger, craving for eating sweets, GERD, } \\
\text { complications and re-operations. }\end{array}$ & - \\
\hline $\begin{array}{l}\text { Howard } \\
1995\end{array}$ & $\begin{array}{l}\text { Design: RCT, Single centre } \\
\text { Sample Size: } 42 \\
\text { Follow-up: up to } 78 \\
\text { months } \\
\text { Country: USA }\end{array}$ & $\begin{array}{l}\text { Age: } 37.3(2.1)^{*} \\
\% \text { Female: } 78.5 \\
\text { BMI: not reported } \\
\text { WT: max. } 148 \\
(2 I .5)^{*} \\
\text { *Standard error }\end{array}$ & $\begin{array}{l}\text { I- GBP } \\
\text { 2-VBG }\end{array}$ & $\begin{array}{l}\text { \%EWL } \\
\text { Early postoperative complications such as wound dehiscence, } \\
\text { infection and thromboembolism, and late complications } \\
\text { including hernia, wound problems, peptic ulcer, gall bladder, } \\
\text { disease, vitamin deficiency and weight regain. }\end{array}$ & - \\
\hline $\begin{array}{l}\text { Kara- } \\
\text { manakos } \\
2008\end{array}$ & $\begin{array}{l}\text { Design: RCT, Single centre } \\
\text { Sample Size: } 32 \\
\text { Follow-up: } 12 \text { months } \\
\text { Country: Greece }\end{array}$ & $\begin{array}{l}\text { Age: } 33.8(8) \\
\% \text { Female: } 84.3 \\
\text { BMI: } 45.8(3.6) \\
\text { WT: } 123.6(16.4)\end{array}$ & $\begin{array}{l}\text { I- LRYGP } \\
\text { 2- LSG }\end{array}$ & $\begin{array}{l}\text { BMI, \%EWL. } \\
\text { Blood level of glucose, triglycerides, cholesterol. And high } \\
\text { and low density lipoprotein cholesterol, Hb, liver function } \\
\text { tests as well as fasting ghrelin and fasting PYY and appetite } \\
\text { assessment. } \\
\text { BMI, \% EWL. }\end{array}$ & ++ \\
\hline Lee 2004 & $\begin{array}{l}\text { Design: RCT, Single centre } \\
\text { Sample Size: } 80 \\
\text { Follow-up: up to } 30 \\
\text { months Country: Taiwan }\end{array}$ & $\begin{array}{l}\text { Age: } 32(8.2) \\
\% \text { Female: } 70 \\
\text { BMI: } 43.1(6.8) \\
\text { WT: II } 9.8(23.8)\end{array}$ & $\begin{array}{l}\text { I- LRYGB } \\
\text { 2- LVBG }\end{array}$ & $\begin{array}{l}\text { Operative time, estimated blood loss, dosages required during } \\
\text { hospital stay, length to postoperative flatus passage, hospital } \\
\text { stay, early, late and major complications. } \\
\text { Quality of life assessment. }\end{array}$ & + \\
\hline $\begin{array}{l}\text { MacLean } \\
1995\end{array}$ & $\begin{array}{l}\text { Design: RCT, Single centre } \\
\text { Sample Size: } 106 \\
\text { Follow-up: up to } 84 \text { months } \\
\text { Country: Canada }\end{array}$ & $\begin{array}{l}\text { Age: } 39.4(8.6) \\
\text { \% Female: not } \\
\text { reported } \\
\text { BMI: } 49(6.9) \\
\text { WT: not reported }\end{array}$ & $\begin{array}{l}\text { I- RYGB } \\
\text { 2-VBG }\end{array}$ & $\begin{array}{l}\text { BMI, \% EWL, Reinhold classification } \\
\text { Reoperation rate. }\end{array}$ & - \\
\hline $\begin{array}{l}\text { Mingrone } \\
2003\end{array}$ & $\begin{array}{l}\text { Design: RCT, Single centre } \\
\text { Sample Size: } 79 \\
\text { Follow-up: I } 2 \text { months Coun- } \\
\text { try: Italy }\end{array}$ & $\begin{array}{l}\text { Age: } 30-45 \\
\% \text { Female: } 65 \\
\text { BMI: } 48.1(7.3) \\
\text { WT: } 136.4\end{array}$ & $\begin{array}{l}\text { 1- BPD } \\
\text { 2- Diet }\end{array}$ & $\begin{array}{l}\text { BMI, Weight. } \\
\text { Body composition and adipose tissue distribution, hormone } \\
\text { measurements, as well as metabolic investigations. }\end{array}$ & - \\
\hline $\begin{array}{l}\text { Nguyen } \\
2009\end{array}$ & $\begin{array}{l}\text { Design: RCT, Single centre } \\
\text { Sample Size: } 197 \\
\text { Follow-up: } 48 \text { months Coun- } \\
\text { try: USA }\end{array}$ & $\begin{array}{l}\text { Age: } 43.6(10.4) \\
\% \text { Female: } 76.5 \\
\text { BMI: } 46.5(5.4) \\
\text { WT: I } 31.1 \text { (2I.I) }\end{array}$ & $\begin{array}{l}\text { I- LRYGB } \\
\text { 2- LAGB }\end{array}$ & $\begin{array}{l}\text { BMI, \% EWL. } \\
\text { Perioperative and late outcomes, weight loss, quality of life } \\
\text { and costs. } \\
\text { Operative time, estimated blood loss, length of hospital stay, } \\
\text { number of patients requiring intensive care unit (ICU) stay, } \\
\text { time to return to normal activities and work, morbidity and } \\
\text { mortality. }\end{array}$ & ++ \\
\hline $\begin{array}{l}\text { Nilsell } \\
2001\end{array}$ & $\begin{array}{l}\text { Design: RCT, Single centre } \\
\text { Sample Size: } 59 \\
\text { Follow-up: up to } 60 \text { months } \\
\text { Country: Sweden }\end{array}$ & $\begin{array}{l}\text { Age: } 38.5 \text { (19-59) } \\
\% \text { Female: } 76.0 \\
\text { BMI: } 43.3(4.6) \\
\text { WT: I } 23.5(17.7)\end{array}$ & $\begin{array}{l}\text { I- AGB } \\
\text { 2-VBG }\end{array}$ & $\begin{array}{l}\text { Complications, need for revisional surgery, reflux symptoms } \\
\text { and the patient's own evaluation. }\end{array}$ & + \\
\hline
\end{tabular}


Table Continued....

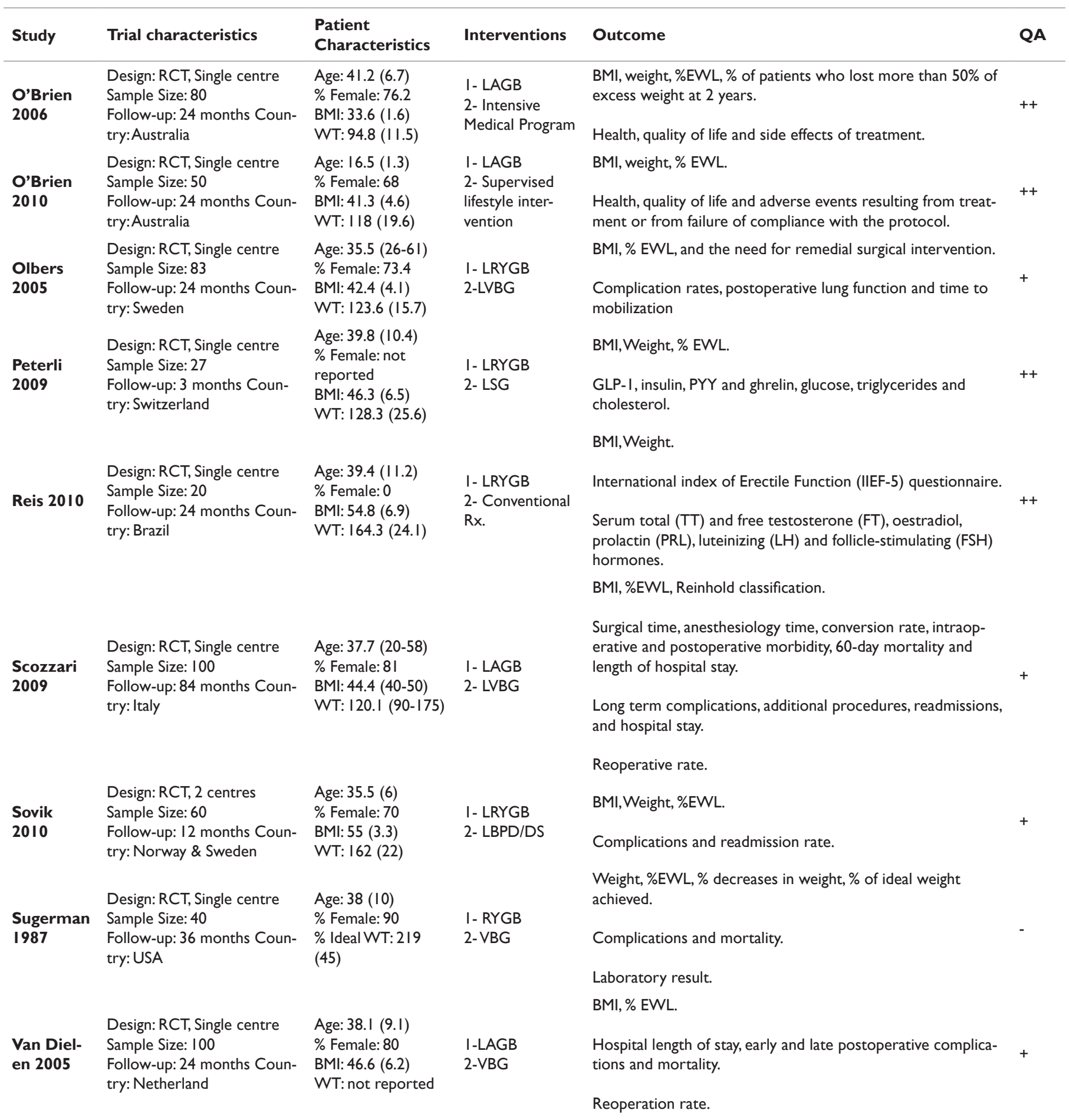

$\mathrm{QA}=$ Qualitative Assessment

All the studies reported on weight changes but used different measures, mostly BMI, weight and percentage of excess weight loss. Resolutions of co-morbidities were reported in eight trials ${ }^{15-17,19-23}$ (Table 1).

\section{Risk of bias}

We assessed the risk of bias for all the included studies; adequate concealment methods were described in three studies. ${ }^{13,16,29}$ Most other trials did not report the allocation process in sufficient details to determine concealment. Four trials reported that outcome assessors were not blinded ${ }^{15-17,27}$ one trial was blinded ${ }^{21}$ and the remaining trials did not report blinding. Methods of handling missing data and drop-outs were also assessed; three trials provided the number of dropouts along with the reasons for the dropout. ${ }^{15,28,30}$ Six trials did not report the reasons for the dropout. ${ }^{14,16,17,24,27,29}$ Two trails did not report on missing data. ${ }^{23,25}$ Adverse events were either not reported or not reported adequately in five trials. ${ }^{13,18,21,22,27}$ All outcomes were pre-specified in the methods section and reported as results in four trials. $^{14,16,28,29}$ 


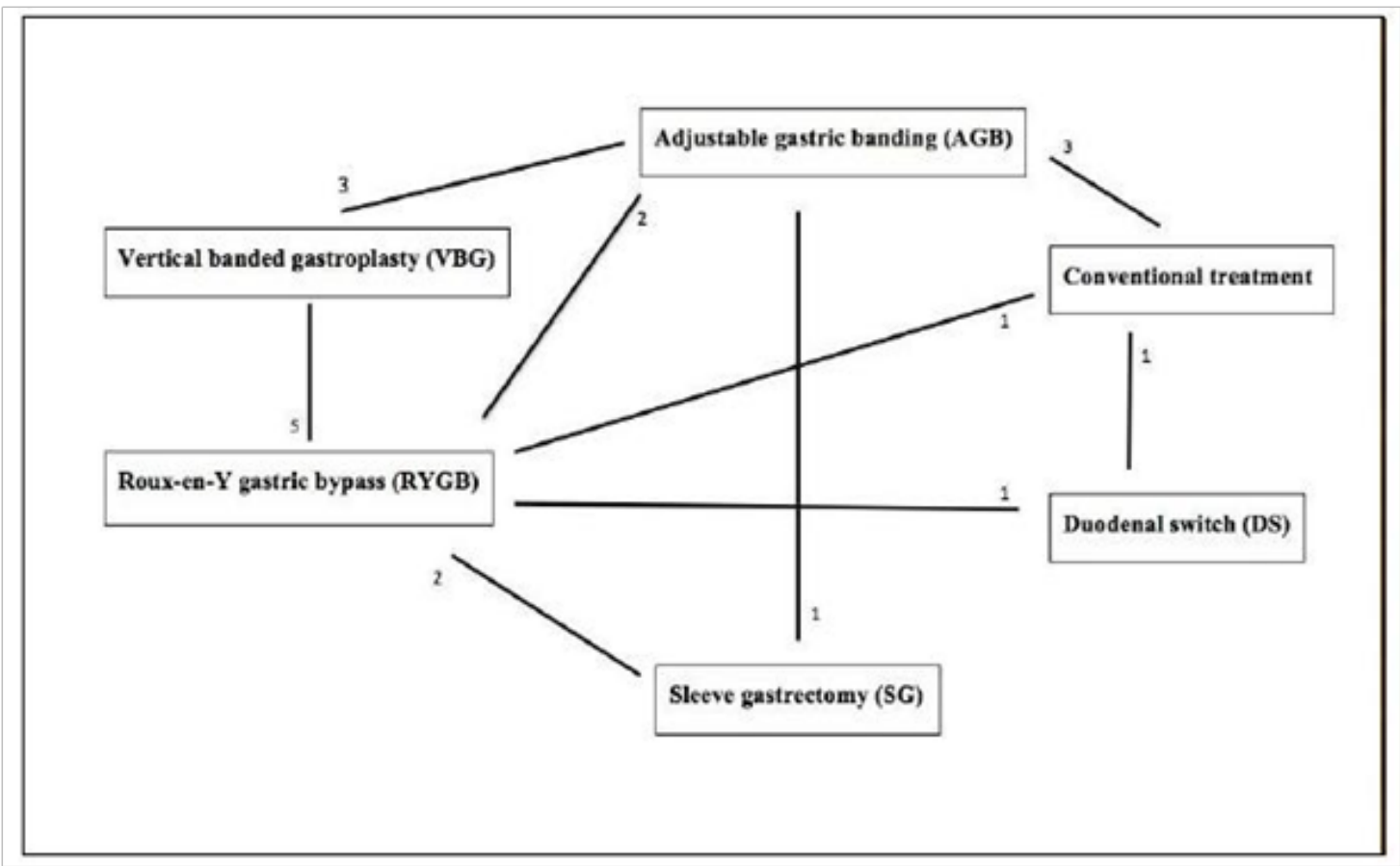

Figure $\mathbf{2}$ Network of comparisons of surgical and non-surgical interventions.

Publication bias and other sensitivity analyses: There were too few studies in any particular comparison to assess publication bias or sensitivity analysis.

\section{Outcomes}

Weight changes: There were three measured primary end points for weight changes in the meta-analysis: percent of excess weight loss (\%EWL), body mass index loss (BMI), and weight loss (WT) in Kilograms, measured at one, two and three years.

EWL at one year: Based on the evidence at 1year, BPD/DS produced a significantly superior $\%$ EWL compared to LRYGB [MD
$20.4 \%$ (95\% CI: 14.3 to 26.5)] and conventional therapy [MD 49.8\% (95\% CI: 44.7 to 54.9)]. However, when compared to LAGB and LVBG at 1year, LRYGB resulted in a significantly superior weight loss [MD 20.5\% (95\% CI: 5.61 to 35.35) and MD 9.5\% (95\% CI: 2.76 to 16.32 ). LVBG had a better weight loss at one year compared to LAGB [MD $-23.1(95 \% \mathrm{CI}$ : -30.9 to -15.20$)]$. In terms of open techniques, RGYB had a better weight loss compared to open VBG and open VBG was also superior when compared to LAGB. Finally sleeve gastrectomy was superior to both LAGB and LRYGB [MD -16.3 (95\% CI: - 26.09 to -6.5$)]$ and [MD -9.2 (95\% CI: -18.07-0.33)] respectively (Figure 3). 14,16,18,22,23,25-27

\begin{tabular}{|c|c|c|c|c|c|}
\hline Study or Subgroup & Mean Difference & \multicolumn{2}{|r|}{ Mean Difference } & \multicolumn{2}{|c|}{$\begin{array}{l}\text { Mean Difference } \\
\text { IV, Fixed, } 95 \% \mathrm{Cl}\end{array}$} \\
\hline BPD/DS vsLRYGB & -20.4 & 3.1225 & $-20.40[-26.52,-14.28]$ & + & \\
\hline Conventional Rx vs BPD/DS & 49.8 & 2.6174 & $49.80[44.67,54.93]$ & & + \\
\hline Conventional Rx vs LAGB & 37.5 & 6.944 & $37.50[23.89,51.11]$ & & $\longrightarrow$ \\
\hline LAGB vs LRYGB & 20.49 & 7.592 & $20.49[5.61,35.37]$ & & $\longrightarrow$ \\
\hline LVBG vs LAGB & -23.1 & 4.0001 & $-23.10[-30.94,-15.26]$ & + & \\
\hline LVBG vs LRYGB & 9.54 & 3.4592 & $9.54[2.76,16.32]$ & & + \\
\hline Open VBG vs Open RYGB & 24.69 & 2.5356 & $24.69[19.72,29.66]$ & & + \\
\hline Open VGB vs LAGB & -17.8 & 4.6123 & $-17.80[-26.84,-8.76]$ & + & \\
\hline Sleeve vs LAGB & -16.3 & 4.995 & $-16.30[-26.09,-6.51]$ & $\rightarrow$ & \\
\hline Sleeve vs LRYGB & -9.2 & 4.5256 & $-9.20[-18.07,-0.33]$ & $\rightarrow$ & \\
\hline & & & & $\begin{array}{ll} \\
-100 & -50 \\
\text { Favours } & \text { Treatment } A\end{array}$ & $\begin{array}{|cc|}1 & 50 \\
\text { Favours Treatment B }\end{array}$ \\
\hline
\end{tabular}

Figure 3 Excess Weight loss at lyear interval.

At 2years when compared to conventional therapy, LRYGB produced a significantly greater percent excess weight loss [MD $74.6 \%$ (95\% CI: 61.7 to 87.5$)] .^{13}$

At 3year time interval, one study compared EWL between LAGB and LRYGB with results favoring LRYGB [MD 22.18\% (95\% CI: 12.66 to 31.70$)]{ }^{14}$ Furthermore, open RYGB had significantly better results when compared to open VBG [MD $27.5 \%$ (95\% CI: 20.09 to $34.9)]^{26}$ (Figure 4).
BMI: LRYGB produced a significantly greater body mass index unit loss compared to LAGB [MD $3.7 \mathrm{~kg} / \mathrm{m}^{2}$ (95\% CI: 1.2 to 6.2 )] and LVBG [MD $2.98 \mathrm{~kg} / \mathrm{m}^{2}$ (95\% CI: 0.49 to 5.47$\left.)\right]$. When compared to LAGB, LVBG had better BMI loss [MD -4.9 (95\% CI: -6.1 to -3.6)]. Sleeve gastrectomy had better BMI loss at one year when compared to both LAGB and LRYGB (Figure 5). ${ }^{15,18,19,22,23,29}$ At 2year interval LAGB had favorable BMI improvement when compared to conventional therapy [MD 7.55 (95\% CI: 4.93 to 10.17$)],{ }^{17}$ however, LVBG had favorable outcome when compared to LAGB during the 
same time period [MD -4.6 (95\% CI: -5.89 to -3.31$)] .{ }^{29}$ At 3 year time point, LRYGB had favorable results compared to LAGB [MD 6.97 (95\% CI: 5.62 to 8.32$)] .^{19}$

-Weight loss: BPD/DS produced significantly more weight loss compared to LRYGB at 1year [MD $19 \mathrm{~kg}$ (95\% CI: 7.8 to 30.2$)$ ] and more profound results compared to conventional therapy at 1year [MD $35 \mathrm{~kg}$ (95\% CI: 25.8 to 44.8$)]$. Open VBG produced significantly better weight loss when compared to ABG, yet, significantly worse weight loss when compared to open RYGB (Figure 6). ${ }^{16,18,24,26}$ At 3years, LRYGB produced favorable weight loss results compared to LAGB [MD 16.3 (95\% CI: 7.83 to 24.77)] (Figure 7). ${ }^{19}$

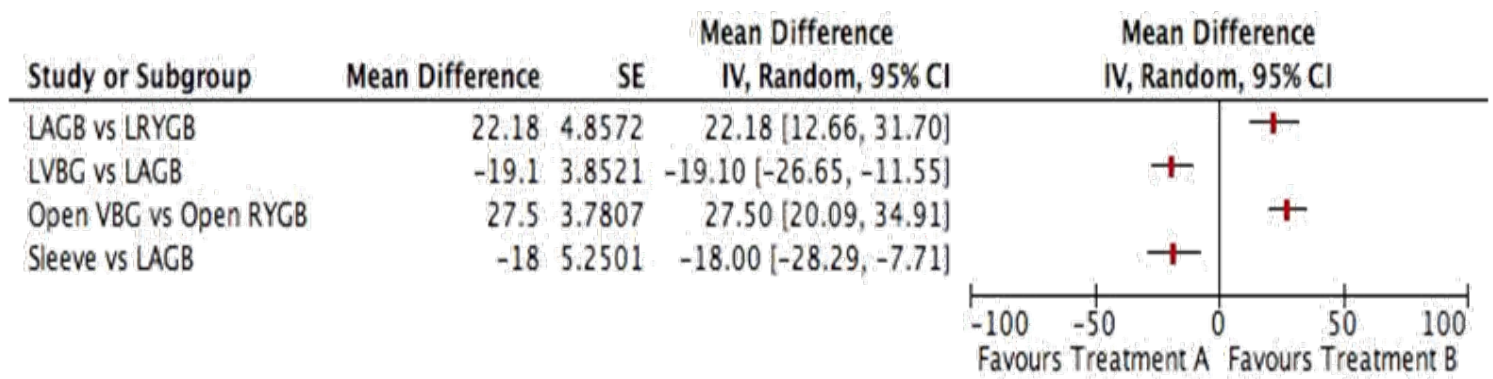

Figure 4 Excess Weight loss at 3year interval.

\begin{tabular}{|c|c|c|c|c|c|}
\hline \multirow{2}{*}{$\begin{array}{l}\text { Study or Subgroup } \\
\text { BPD/DS vsLRYGB }\end{array}$} & \multirow{2}{*}{$\begin{array}{r}\text { Mean Difference } \\
-6.4\end{array}$} & \multirow{2}{*}{$\begin{array}{r}\text { SE } \\
0.9031\end{array}$} & \multirow{2}{*}{$\begin{array}{l}\text { Mean Difference } \\
\text { IV, Random, 95\% CI } \\
-6.40[-8.17,-4.63]\end{array}$} & \multicolumn{2}{|c|}{$\begin{array}{c}\text { Mean Difference } \\
\text { IV, Random, 95\% CI }\end{array}$} \\
\hline & & & & + & \\
\hline Conventional Rx vs BPD/DS & 11.5 & 1.6939 & $11.50[8.18,14.82]$ & & + \\
\hline Conventional Rx vs LAGB & 3.1 & 0.4847 & $3.10[2.15,4.05]$ & & + \\
\hline LAGB vs LRYGB & 3.7 & 1.2704 & $3.70[1.21,6.19]$ & & + \\
\hline LVBG vs LAGB & -4.9 & 0.6582 & $-4.90[-6.19,-3.61]$ & + & \\
\hline LVBG vs LRYGB & 2.98 & 1.2704 & $2.98[0.49,5.47]$ & & + \\
\hline Open VGB vs LAGB & -3.8 & 1.25 & $-3.80[-6.25,-1.35]$ & + & \\
\hline Sleeve vs LAGB & -9.5 & 0.75 & $-9.50[-10.97,-8.03]$ & + & \\
\hline \multirow[t]{2}{*}{ Sleeve vs LRYGB } & -1.1 & 1.2653 & $-1.10[-3.58,1.38]$ & & \\
\hline & & & & $\begin{array}{ll}\qquad-50 & -25 \\
\text { Favours } & \text { Treatment A }\end{array}$ & 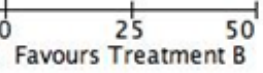 \\
\hline
\end{tabular}

Figure 5 Body mass index loss at lyear interval.

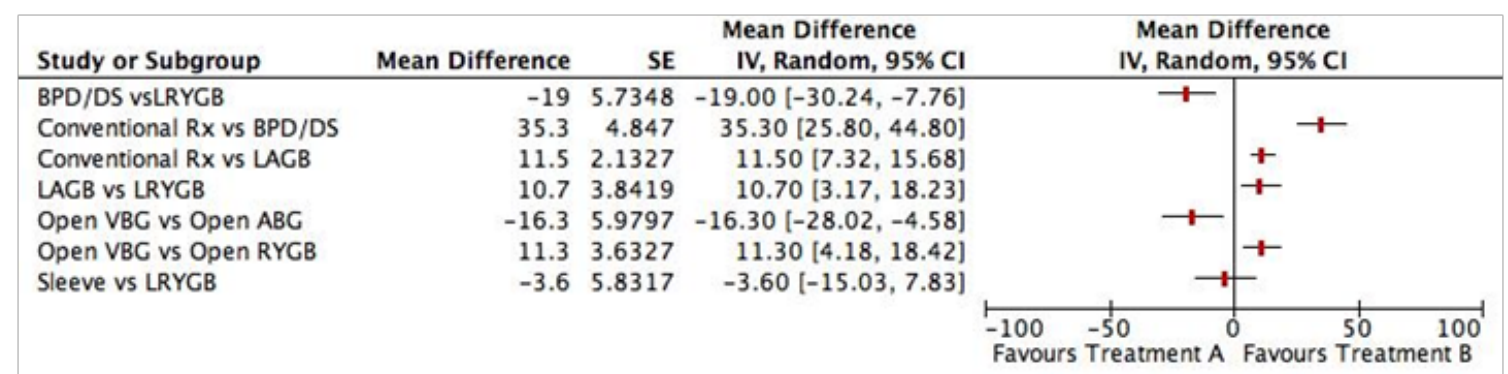

Figure 6 Weight loss at lyear interval.

\begin{tabular}{|c|c|c|c|c|c|}
\hline Study or Subgroup & Mean Difference & \multirow{2}{*}{$\begin{array}{r}\text { SE } \\
4.3215\end{array}$} & $\begin{array}{l}\text { Mean Difference } \\
\text { IV, Random, 95\% CI }\end{array}$ & \multicolumn{2}{|c|}{$\begin{array}{c}\text { Mean Difference } \\
\text { IV, Random, 95\% CI }\end{array}$} \\
\hline LAGB vs LRYGB & 16.3 & & $16.30[7.83,24.77]$ & & 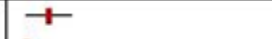 \\
\hline Open VBG vs Open ABG & 8 & 6.2909 & $8.00[-4.33,20.33]$ & & 1 \\
\hline Open VBG vs Open RYGB & 11.3 & 3.6327 & $11.30[4.18,18.42]$ & & + \\
\hline & & & & $\begin{array}{ll}-100 & -50 \\
\text { Favours } & \text { Treatment A }\end{array}$ & Favours Treatment B \\
\hline
\end{tabular}

Figure 7 Weight loss at 3year interval.

Resolution of co-morbidities: Five RCTS ${ }^{13,15-18}$ compared surgical to nonsurgical interventions. Four of the five were conducted in adult ${ }^{13,16-18}$ populations and one in adolescents. ${ }^{15}$ Of the five RCTS: three compared adjustable gastric banding to conventional. ${ }^{15-17}$ One trial $^{13}$ compared LRYGB to conventional therapy and one $\mathrm{RCT}^{18}$ compared biliopancreatic diversion and duodenal switch to diet. Of those studies, one trial, ${ }^{17}$ compared LAGB to conventional therapy in type 2 diabetic patients and found a higher remission rate in the surgical group $(73 \%$ vs $13 \% \mathrm{P}<0.001)$. In addition, patients in this study discontinued antihypertensive medications $(70 \%$ vs $0 \%$ $\mathrm{P}<0.001)$ and lipid lowering agents $(67 \%$ vs $13 \% \mathrm{P}=0.02)$. Similar findings were reported by two other trials ${ }^{15,16}$ compared LAGB to conventional therapy and found more patients with resolution of metabolic syndrome following bariatric surgery ( $93 \%$ vs $46 \%$ $\mathrm{P}=0.006)$ and $(100 \%$ vs $60 \% \mathrm{P}<0.025)$ respectively. 
One trial ${ }^{19}$ compared LRYGB to LAGB and reported resolution of diabetes, sleep apnea, and hyperlipidemia in all patients who suffered from these co-morbidities prior to entrance into the study. Himpens $^{23}$ compared sleeve gastrectomy to LAGB and found resolution of gastroesophageal reflux disease (GERD) in more than $75 \%$ of participants following surgery. Karamanakos ${ }^{21}$ compared LSG to LRYGB and found significant reduction in glucose and triglyceride levels in both groups following surgery, as well as resolution of diabetes in all participants in the LRYGB group. Van Dielen $^{20}$ compared LAGB to open VBG and found that all comorbidities had a tendency to decrease over time in both groups. Joint and pulmonary problems as well as diabetes showed the greatest improvement in co-morbidities after surgery. Lee ${ }^{25}$ compared LRYGB to LVBG and found significant reduction in obesity-related clinical and laboratory abnormalities including blood pressure, blood glucose level, cholesterol level, triglyceride levels, uric acid levels, and liver function test.

\section{Discussion}

Obesity is a major medical and socioeconomic problem associated with different illnesses among them type 2 diabetes mellitus, high blood pressure, gallstones, certain types of cancer, gastroesophageal reflux disease, fatty liver, degenerative joint diseases, obstructive sleep apnea syndrome, and psychiatric diseases. Over the past two decades, the use of bariatric surgery to treat morbid obesity has increased dramatically. Surgery is markedly superior to conservative treatment with respect to weight reduction and alleviation of illnesses caused by obesity.

In this study, we incorporated 19 RCTs evaluating the effectiveness of surgical and non- surgical treatments for obesity and whether they modify clinically important outcomes, including weight loss, comorbidity modifications to diabetes, hyperlipidemia, hypertension, and obstructive sleep apnea in adolescents and the adult obese population. The results of this study confirmed that bariatric surgery resulted in greater weight loss when compared to non-surgical treatment. Weight loss was also associated with resolution and/ or improvement of obesity related co-morbidities such as diabetes, hypertension, hyperlipidemia, and sleep apnea. The effectiveness of bariatric procedures varied across the procedures, where malabsorptive procedures such as biliopancreatic diversion had the greatest weight loss results. Second to BPD was sleeve gastrectomy. Malabsorptive and restrictive procedures such as Roux-en-Y gastric bypass resulted in intermediate weight loss and restrictive procedures such as AGB and VBG caused the least amount of weight loss.

Our results are in an agreement with other reports from observational studies as well as systematic reviews and meta-analysis. In 2004, Sjostrom et al., ${ }^{31}$ published a land mark cohort study in the New England Journal of Medicine with a total of 4047 participants, of these 2010 underwent bariatric and all followed for 10years, found that weight has increased in the conventional treated group by $1.6 \%$, where weight has decrease in the surgical group by $16.1 \%$. Recovery from obesity related

Co-morbidities were more frequent in the surgical group than in the conventional group. A systematic review and meta-analysis that included observational studies to evaluate the impact of bariatric surgery on type 2 diabetes and found to have dramatic impact where $78.1 \%$ of the participants in the surgical group had complete resolution of type 2 diabetes and $86.6 \%$ had their diabetes improved or resolved, as well as similar result in term of weight loss, where biliopancreatic diversion/duodenal switch had the greatest weight loss followed by gastric bypass, and least for banding procedures. ${ }^{32}$

One of the limitations of this study is that most trials only provided short term follow-up (median follow-up was 2years) and trials which provided a longer follow-up had high dropout rates. In addition, published trials did not provide enough detail to adequately assess the risk of bias, which consequently remains uncertain. Only 3 trials reported adequate concealment, which is considered a low risk of selection bias. Some variance measures necessary for meta-analysis were missing from a few trials, and this is considered a limitation to this review, as not all the data were available. Some procedures were assessed in only two trials such as sleeve gastrectomy and biliopancreatic diversion, and some trials did not report on safety at all.

On the other hand, this study also has several strengths. An extensive literature search was performed and provided the most upto-date information on the outcomes of different bariatric procedures. Using two reviewers, the inclusion or exclusion of studies and data extraction were performed independently and therefore more accurately. In addition, we did not exclude potential studies due to language, publication status or year of publication. Another strength of this study is that we assessed not only the impact of bariatric procedures on weight reduction, but we also included its impact on the resolution of obesity related co-morbidities and compared different bariatric procedures to each other and to non operative conventional management.

In summary, this study has demonstrated that bariatric surgery is more effective than conventional therapy for the treatment of obesity. Weight loss associated with bariatric surgery led to improvement and remission of co-morbidities such as type 2 diabetes, hypertension, hypercholesterolemia, as well as significant reduction in the use of hypoglycemic agents, antihypertensive agents, and lipid lowering agents. Weight loss varied across the procedures, where biliopancreatic diversion with duodenal switch achieved the greatest weight loss, followed by sleeve gastrectomy, gastric bypass, followed by vertical banded gastroplasty, and finally adjustable gastric band achieved the least weight loss.

\section{Acknowledgements}

None.

\section{Conflict of interest}

The author declares no conflict of interest.

\section{References}

1. World Health Organization (WHO). Overweight and Obesity. Factsheet no.311: World Health Organization; 2011.

2. World Health Organization (WHO). Obesity: preventing and managing the global epidemic. Report of a WHO consultation. World Health Organ Tech Rep Ser. 2000;894:1-11.

3. Ogden CL, Li Y, Freedman DS, et al. Smoothed percentage body fat percentiles for U.S. children and adolescents, 1999-2004. Natl Health Stat Report. 2011;43:1-7.

4. Hedley AA, Ogden CL, Johnson CL, et al. Prevalence of overweight and obesity among US children, adolescents, and adults, 1999-2002. JAMA. 2004;291(23):2847-2850.

5. Avenell A, Brown TJ, McGee MA, et al. what are the long-term benefits of weight reducing diets in adults? A systematic review of randomized controlled trials. J Hum Nutr Diet. 2004;17(4):317-335. 
6. Avenell A, Brown TJ, McGee MA, et al. what interventions should we add to weight reducing diets in adults with obesity? A systematic review of randomized controlled trials of adding drug therapy, exercise, behaviour therapy or combinations of these interventions. J Hum Nutr Diet. 2004;17(4):293-316.

7. NIH conference. Gastrointestinal surgery for severe obesity. Consensus Development Conference Panel. Ann Intern Med. 1991;115(12):956961.

8. Sign 50. A guideline developer's handbook. Scottish Intercollegiate Guidelines Network. 2011.

9. Higgins JPT AD. Chapter 8: Assessing risk of bias in included studies. Cochrane Handbook for Systematic Reviews of Interventions. 2012

10. The Nordic Cochrane Centre RevMan 2011 Review Manager (RevMan) 5.1. The Cochrane Collaboration. 2011.

11. Higgins JP, Thompson SG, Deeks JJ, et al. Measuring inconsistency in meta-analyses. BMJ. 2003;327(7414):557-560.

12. Sovik TT, Taha O, Aasheim ET, et al. Randomized clinical trial of laparoscopic gastric bypass versus laparoscopic duodenal switch for super obesity. Br J Surg. 2010;97(2):160-166.

13. Reis LO, Favaro WJ, Barreiro GC, et al. Erectile dysfunction and hormonal imbalance in morbidly obese male is reversed after gastric bypass surgery: a prospective randomized controlled trial. Int J Androl. 2010;33(5):736-744.

14. Nguyen NT, Slone JA, Nguyen XM, et al. A prospective randomized trial of laparoscopic gastric bypass versus laparoscopic adjustable gastric banding for the treatment of morbid obesity: outcomes, quality of life, and costs. Ann Surg. 2009;250(4):631-641.

15. O Brien PE, Sawyer SM, Laurie C, et al. Laparoscopic adjustable gastric banding in severely obese adolescents: a randomized trial. JAMA. 2010;303(6):519-526.

16. O Brien PE, Dixon JB, Laurie C, et al. Treatment of mild to moderate obesity with laparoscopic adjustable gastric banding or an intensive medical program: a randomized trial. Ann Intern Med. 2006;144(9):625633.

17. Dixon JB, O Brien PE, Playfair J, et al. Adjustable gastric banding and conventional therapy for type 2 diabetes: a randomized controlled trial. JAMA. 2008;299(3):316-323.

18. Mingrone G, Greco AV, Giancaterini A, et al. Sex hormone-binding globulin levels and cardiovascular risk factors in morbidly obese subjects before and after weight reduction induced by diet or malabsorptive surgery. Atherosclerosis. 2002;161(2):455-462.

19. Angrisani L, Lorenzo M, Borrelli V. Laparoscopic adjustable gastric banding versus Roux-en-Y gastric bypass: 5-year results of a prospective randomized trial. Surg Obes Relat Dis. 2007;3(2):127-132.
20. Van Dielen FM, Soeters PB, de Brauw LM, et al. Laparoscopic adjustable gastric banding versus open vertical banded gastroplasty: a prospective randomized trial. Obes Surg. 2005;15(9):1292-1298.

21. Karamanakos SN, Vagenas K, Kalfarentzos F, et al. Weight loss, appetite suppression, and changes in fasting and postprandial ghrelin and peptideYY levels after Roux-en-Y gastric bypass and sleeve gastrectomy: a prospective, double blind study. Ann Surg. 2008;247(3):401-407.

22. Peterli R, Wolnerhanssen B, Peters T, et al. Improvement in glucose metabolism after bariatric surgery: comparison of laparoscopic Rouxen-Y gastric bypass and laparoscopic sleeve gastrectomy: a prospective randomized trial. Ann Surg. 2009;250(2):234-241.

23. Himpens J, Dapri G, Cadiere GB. A prospective randomized study between laparoscopic gastric banding and laparoscopic isolated sleeve gastrectomy: results after 1 and 3years. Obes Surg. 2006;16(11):1450 1456.

24. Howard L, Malone M, Michalek A, et al. Gastric Bypass and Vertical Banded Gastroplasty- a Prospective Randomized Comparison and 5Year Follow-up. Obes Surg. 1995;5(1):55-60.

25. Lee WJ, Huang MT, Yu PJ, et al. Laparoscopic vertical banded gastroplasty and laparoscopic gastric bypass: a comparison. Obes Surg. 2004;14(5):626-634

26. MacLean LD, Rhode BM, Forse RA, et al. Surgery for Obesity- An Update of a Randomized Trial. Obes Surg. 1995;5(2):145-150.

27. Nilsell K, Thorne A, Sjostedt S, et al. Prospective randomised comparison of adjustable gastric banding and vertical banded gastroplasty for morbid obesity. Eur J Surg. 2001;167(5):504-509.

28. Olbers T, Fagevik OM, Maleckas A, et al. Randomized clinical trial of laparoscopic Roux-en-Y gastric bypass versus laparoscopic vertical banded gastroplasty for obesity. Br J Surg. 2005;92(5):557-562.

29. Scozzari G, Farinella E, Bonnet G, et al. Laparoscopic adjustable silicone gastric banding Vs laparoscopic vertical banded gastroplasty in morbidly obese patients: long-term results of a prospective randomized controlled clinical trial. Obes Surg. 2009;19(8):1108-1115.

30. Sugerman HJ, Starkey JV, Birkenhauer R. A randomized prospective trial of gastric bypass versus vertical banded gastroplasty for morbid obesity and their effects on sweets versus non-sweets eaters. Ann Surg. 1987;205(6):613-624.

31. Sjostrom L, Lindroos AK, Peltonen M, et al. Lifestyle, diabetes, and cardiovascular risk factors $10 y e a r s$ after bariatric surgery. $N$ Engl J Med. 2004;351(26):2683-2693.

32. Buchwald H, Estok R, Fahrbach $\mathrm{K}$, et al. Weight and type 2 diabetes after bariatric surgery: systematic review and meta-analysis. Am J Med. 2009; 122(3):248-256. 